\title{
INFLUÊNCIA DO CLIMA E DE ROTAS MIGRATÓRIAS DE ESPÉCIES ARBÓREAS SOBRE O PADRÃO FITOGEOGRÁFICO DE FLORESTAS NA REGIÃO SUL DO BRASIL
}

\author{
INFLUENCE OF CLIMATE AND MIGRATION ROUTES OF TREE SPECIES ON THE \\ PHYTOGEOGRAPHY PATTERNS OF FORESTS IN SOUTHERN BRAZIL
}

\author{
Pedro Higuchi ${ }^{1}$ Ana Carolina da Silva ${ }^{2}$ Jean Carlos Budke ${ }^{3}$ Adelar Mantovani ${ }^{4}$ \\ Roseli Lopes da Costa Bortoluzzi ${ }^{5}$ Adriano Antonio Ziger ${ }^{6}$
}

\begin{abstract}
RESUMO
O presente trabalho objetivou avaliar a influência de variáveis bioclimáticas e de rotas migratórias de espécies arbóreas sobre o padrão fitogeográfico de diferentes fitofisionomias florestais da Região Sul do Brasil. Foram extraídas da literatura listas florísticas de espécies arbóreas inventariadas em Floresta Ombrófila Mista (FOM), Floresta Ombrófila Densa (FOD), Floresta Estacional Decidual (FED) e Floresta Estacional Semidecidual (FESD). Para cada área foram obtidas as coordenadas geográficas, a altitude média e as variáveis bioclimáticas associadas à temperatura e à precipitação pluviométrica. A matriz vegetacional passou por uma análise de correspondência retificada (DCA) e, posteriormente, a matriz ambiental foi ajustada à ordenação, sendo as variáveis ambientais $(p \leq 0,001)$ inseridas na forma de vetores. A análise da relação florística entre as áreas em função da heterogeneidade bioclimática existente foi realizada por meio de uma Árvore de Regressão Multivariada (ARM). Os autovalores para os eixos 1 e 2 da DCA foram de 0,49 e 0,25 , respectivamente, indicando elevada substituição de espécies ao longo do eixo 1 , fortemente associada à temperatura média do trimestre mais úmido, à temperatura mínima no mês mais frio, à altitude e à temperatura média anual. Conclui-se que (i) existe maior similaridade florística entre FOM e Florestas Estacionais e (ii) o componente arbóreo das florestas do Sul do Brasil apresenta variações florísticas e fisionômicas associadas à heterogeneidade bioclimática existente e às rotas migratórias.
\end{abstract}

Palavras-chave: Floresta Ombrófila Mista; Floresta Ombrófila Densa; Florestas Estacionais.

\section{ABSTRACT}

This study aimed to evaluate the influence of bioclimatic variables and tree species migration routes on the phytogeographic pattern of different forest physiognomy in southern Brazil. For this proposal, floristic check-lists of tree species of Araucaria Forest (AF), Subtropical Rain Forest (SRF), Seasonal Deciduous Forest (SDF) and Seasonal semi-deciduous Forest (SSF) were extracted from the scientific literature. The vegetation matrix went through a detrended correspondence analysis (DCA) and, subsequently, the environmental matrix was adjusted to the ordination axes. The significant environmental variables $(p \leq$

1 Engenheiro Florestal, Dr. , Professor Adjunto do Departamento de Engenharia Florestal, Centro de Ciências Agroveterinárias, Universidade do Estado de Santa Catarina, Av. Luis de Camões, 2090, CEP 88520-000, Lages (SC), Brasil. higuchip@gmail.com

2 Engenheira Florestal, Dr ${ }^{\mathrm{a}}$, , Professora Adjunto do Departamento de Engenharia Florestal, Centro de Ciências Agroveterinárias, Universidade do Estado de Santa Catarina, Av. Luis de Camões, 2090, CEP 88520-000, Lages (SC), Brasil.carol_sil4@yahoo.com.br

3 Biólogo, Dr., Professor do Departamento de Ciências Biológicas, Universidade Regional Integrada do Alto Uruguai e das Missões, Rua Universidade das Missões, 464, CEP 99700-000, Erechim (RS). budke_jc@yahoo.com.br

4 Engenheiro Agrônomo, Dr., Professor Adjunto do Departamento de Engenharia Florestal, Centro de Ciências Agroveterinárias, Universidade do Estado de Santa Catarina, Av. Luis de Camões, 2090, CEP 88520-000, Lages (SC), Brasil.a2ama@cav.udesc.br

5 Bióloga, Dra ${ }^{\mathrm{a}}$, Professora Adjunto do Departamento de Engenharia Florestal, Centro de Ciências Agroveterinárias, Universidade do Estado de Santa Catarina, Av. Luis de Camões, 2090, CEP 88520-000, Lages (SC), Brasil. rosebortoluzzi@gmail.com

6 Biólogo, Departamento de Ciências Biológicas, Universidade Regional Integrada do Alto Uruguai e das Missões, Rua Universidade das Missões, 464, CEP 99700-000, Erechim (RS), Brasil. ziger10@hotmail.com

Recebido para publicação em 29/03/2011 e aceito em 18/07/2012 
$0.001)$ were plotted as vectors in the ordination diagram. A Multivariate Regression Tree (MRT) was used in order to analyze the floristic relationship among areas in function of bioclimatic variables. The eigenvalues for axis 1 and 2 of the DCA were, respectively, 0.49 and 0.25 , which indicated high species turnover along axis 1 , strongly associated with mean temperature of the wettest quarter, minimum temperature of the coldest month, altitude and annual average temperature. The results allowed the conclusion that (i) there is greater floristic similarity between Araucaria Forest and Seasonal Forests, and (ii) the tree component of southern Brazil forests shows physiognomic and floristic variation in response to bioclimatic heterogeneity and migration routes.

Keywords: Araucaria forests; Rain forests; Seasonal forests.

\section{INTRODUÇÃO}

A Região Sul do Brasil apresenta vegetação natural composta por um mosaico de formações florestais e campestres. As formações florestais fazem parte do Bioma Mata Atlântica (OLIVEIRA-FILHO e FONTES, 2000) e, em sua maioria, são classificadas de acordo com o IBGE (1992) como Floresta Ombrófila Mista (FOM), Floresta Estacional Decidual (FED), Floresta Estacional Semidecidual (FESD) e Floresta Ombrófila Densa (FOD). A FOM, também conhecida como Floresta com Araucária, ocorre nas áreas de maior altitude no Planalto Sulbrasileiro, separando geograficamente a Floresta Ombrófila Densa (FOD), que ocorre no leste, abrangendo principalmente a região litorânea $\mathrm{e}$ as encostas da Serra Geral e Serra do Mar, das Florestas Estacionais Deciduais (FED) e Semideciduais (FESD), que ocorrem predominantemente no oeste, principalmente na Bacia do Rio Paraná e na região Alto Uruguai (JARENKOW e BUDKE, 2010). As formações campestres destacam-se nas planícies de baixa altitude, presentes no interior do Rio Grande do Sul, e também em áreas de maior altitude como na Coxilha Rica, no Planalto Sul-catarinense, e nos Campos de Cima da Serra, no Rio Grande do Sul.

Devido ao histórico processo de ocupação de terras, caracterizado principalmente pela exploração de espécies madeiráveis e subsequente fragmentação florestal, além da expansão de atividades agropecuárias, as áreas de floresta original foram drasticamente reduzidas. Desta forma, a conservação das florestas remanescentes é importante, pois além de apresentarem elevada diversidade residual (TABARELLI et al., 1999), estas desempenham serviços ambientais, como o sequestro de $\mathrm{CO}_{2}$ atmosférico, proteção do solo, manutenção do ciclo hidrológico e proteção dos cursos d'água (LAURANCE, 1999), e, no contexto de metapopulações, podem funcionar como stepping stones, capazes de facilitar o fluxo gênico entre populações
(KAGEYAMA et al., 2001). Estudos que procuram entender a distribuição geográfica de espécies nestas florestas são fundamentais, pois permitem subsidiar estratégias de conservação e restauração ambiental, e auxiliam na previsão dos impactos de mudanças climáticas futuras sobre a vegetação natural.

Dentre os principais fatores que influenciam a distribuição de espécies, destacam-se o clima e os paleoeventos de natureza variada, tais como a expansão e retração vegetacional em função de alterações climáticas passadas (FERNANDES, 2003). $O$ estudo da relação entre a vegetação e o clima tem sido realizado por vários autores, considerando escalas espaciais distintas. No Domínio da Mata Atlântica na Região Sudeste do Brasil, por exemplo, tem sido observada forte influência do regime de precipitação, principalmente no que se refere à sazonalidade das chuvas, e de alterações altitudinais, associadas a mudanças na temperatura, sobre a composição florística de florestas tropicais úmidas e estacionais semideciduais (OLIVEIRA-FILHO e FONTES, 2000).

Considerando que o clima atual na Região Sul, caracterizado por ser predominantemente mesotérmico e sem estação seca, favorece a ocorrência de florestas, a existência de campos naturais sob as condições climáticas reinantes sempre intrigou os cientistas (BEHLING e PILLAR, 2007). Porém, estudos recentes revelam que a vegetação campestre representa remanescentes naturais dos períodos glaciais pretéritos, em que o clima era mais seco. Como o clima é extremamente dinâmico, é natural que a distribuição das espécies arbóreas se altere ao longo do tempo, como resposta às flutuações climáticas, sendo que estudos geomorfológicos indicam pelo menos dois períodos secos no passado mais recente: um muito severo durante o Pleistoceno e um menos intenso durante o Holoceno (LEDRU, 1993).

Na região do Planalto Sul-brasileiro, durante o último período glacial até o Holoceno Inicial e Médio, a vegetação predominante era de campos 
naturais, com a Floresta com Araucária ocupando microssítios úmidos, como as áreas próximas das redes de drenagem (BEHLING et al., 2004). O domínio de campos nessa área supõe-se ter ocorrido devido a um clima mais seco e frio, durante o último período glacial, e seco e quente durante o Holoceno Inicial (BEHLING, 1997). A primeira expansão de Araucária saindo dos vales úmidos para ocupar áreas elevadas ocorreu no final do Holoceno (28501530 anos AP), indicando um clima mais úmido. Uma forte expansão da Floresta com Araucária, a partir das redes de drenagem, só ocorreu a cerca de 1500 anos AP na região dos Campos Gerais, no Paraná, e apenas 1000 no Estado de Santa Catarina (BEHLING, 1997; BEHLING et al., 2004). Atualmente, há evidências de que, eliminando a criação de gado e a ocorrência de fogo, a Floresta com Araucária tenderia a se expandir sobre os campos (BEHLING e PILLAR, 2007).

Da mesma forma que a Floresta com Araucária vem se expandindo sobre áreas campestres nas áreas de maior altitude no Planalto Sul-brasileiro, as Florestas Estacionais e Floresta Ombrófila Densa se expandiram sobre áreas campestres quando o clima mudou de seco para úmido, principalmente nos últimos 1000 anos. As Florestas Estacionais ocuparam os locais de menores altitudes, vindo do norte, tendo como rota as Bacias dos Rios Paraná-Uruguai (RAMBO, 1951), na região oeste. A Floresta Ombrófila Densa, também a partir do norte em sentido ao sul (rota norte-sul), ocupou as planícies litorâneas e encostas da Serra do Mar, sendo que, para o Rio Grande do Sul, Rambo (1951) propôs que a entrada de espécies do contingente atlântico no estado se deu também no interior a partir da "Porta de Torres", que corresponde à faixa estreita que ocorre desde Torres até Osório, no litoral norte gaúcho. O estudo de Carnaval et al. (2009) demonstrou que, como o clima da Mata Atlântica sensu stricto na Região Sul do Brasil era relativamente instável, as regiões mais ao norte, com o clima mais estável, serviram como refúgio climático de espécies neotropicais durante o Pleistoceno Tardio.

Considerando a dinâmica da vegetação durante o Quaternário Tardio e as variações espaciais do clima existentes na Região Sul do Brasil, o presente trabalho tem como proposta analisar os padrões fitogeográficos do componente arbóreo das principais formações florestais da Região Sul do Brasil, com o objetivo de melhor compreender a influência destes fatores sobre o relacionamento florístico entre as diferentes formações florestais existentes na região. As hipóteses testadas são: (i) como a área de ocorrência da Floreta Ombrófila Mista se localiza em sua maior extensão nas vertentes continentais dos principais rios da região (e.g. Rio Uruguai), essas apresentam maior afinidade florística com as Florestas Estacionais, devido ao maior fluxo migratório de espécies; (ii) o componente arbóreo das florestas sul-brasileiras apresenta variações florísticas e fisionômicas devido à heterogeneidade bioclimática existente, associada, principalmente, à altitude, à temperatura e à precipitação pluviométrica.

\section{MATERIAL E MÉTODO}

\section{Compilação das listagens florísticas e das variáveis climáticas}

Foram compiladas da literatura científica e de trabalhos ainda não publicados, as listas florísticas de 58 áreas de florestas da Região Sul do Brasil, pertencentes às fisionomias de FOM, FOD, FESD e FED, situadas predominantemente nas planícies litorâneas e encostas da Serra do Mar (rota migratória do Leste), nas bacias hidrográficas dos rios Paraná e Uruguai (rota migratória do Oeste) e na região do planalto (Floresta com Araucária) (Tabela 1), cujas localizações geográficas podem ser observadas na Figura 1. Foram extraídas das listas florísticas apenas espécies arborescentes. As informações referentes às espécies passaram por uma revisão detalhada a respeito do hábito e de sinonímias botânicas. Apesar das áreas apresentarem diferentes metodologias amostrais, o que representa uma fonte de viés estatístico, foi considerado que, para os objetivos propostos e para a escala espacial considerada, o valor da informação florística acrescida pela inclusão de áreas com metodologias distintas é maior do que o custo gerado devido ao viés estatístico. Por isso, optou-se pela inclusão de áreas com metodologias diferenciadas, assumindo-se que a incerteza reduzida com o acréscimo das informações contidas nessas áreas, seja maior do que a incerteza gerada devido ao viés estatístico.

Os dados climáticos (1960-1990) e de altitude referentes a cada uma dessas áreas foram extraídos do banco de dados do WorldClim (HIJMANS et al., 2005). As variáveis climáticas utilizadas foram: temperatura média anual (b1), média da amplitude térmica diária (b2), isotermalidade (b3), sazonalidade térmica (b4), temperatura máxima no mês mais quente (b5), temperatura mínima no mês mais 
TABELA 1: Levantamentos florísticos e fitossociológicos das 58 áreas de florestas da Região Sul do Brasil, pertencentes a diferentes fisionomias utilizadas nas análises florísticas.

TABLE 1: Floristic and phytosociological surveys of 58 forest areas in southern Brazil, belonging to different physiognomy used in floristic analysis.

\begin{tabular}{|c|c|c|c|c|}
\hline Município & Localidade & $\mathrm{E}$ & Autor(es) & M.A. e N.I \\
\hline Araucária & - & PR & Barddal et al., 2004 & $\begin{array}{l}\text { Parcelas, PAP }<15 \mathrm{~cm} \mathrm{e} \\
\mathrm{h}>1,30 \mathrm{~m}\end{array}$ \\
\hline Arapoti & Rio das Cinzas & PR & Blum et al., 2003 & Parcelas, DAP $>10 \mathrm{~cm}$ \\
\hline Pinhais & Alphaville Graciosa & PR & Seger et al., 2005 & Parcelas, $\mathrm{PAP} \geq 15 \mathrm{~cm}$ \\
\hline São João do Triunfo & Estação São João do Triunfo & PR & Sanquetta et al., 2000 & Parcelas, DAP $>10 \mathrm{~cm}$ \\
\hline Curitiba 1 & Capão do Tigre & PR & Rondon Neto et al., 2002a & Parcelas, DAP $\geq 5 \mathrm{~cm}$ \\
\hline Curitiba 2 & Parque Municipal do Barigui & PR & Kozera et al., 2006 & Quadrantes, PAP $\geq 10 \mathrm{~cm}$ \\
\hline Irati & $\begin{array}{l}\text { Parque Ambiental Rubens } \\
\text { Dalle Grave }\end{array}$ & PR & Valério et al., 2008a & Parcelas, DAP $\geq 10 \mathrm{~cm}$ \\
\hline Morretes & Parque Estadual do Marumbi & PR & Silva, 1994 & Quadrantes, PAP $\geq 15 \mathrm{~cm}$ \\
\hline Guarapuava & $\begin{array}{l}\text { Fazendas Três Capões e } \\
\text { Trindade }\end{array}$ & PR & Kataoka-Silva, 2006 & Excursões e transectos \\
\hline Matinhos & Litoral 1 & PR & Galvão et al., 2002 & Parcelas, DAP $\geq 10 \mathrm{~cm}$ \\
\hline Pontal do Paraná & Litoral 2 & PR & Galvão et al., 2002 & Parcelas, DAP $\geq 10 \mathrm{~cm}$ \\
\hline Guaraqueçaba & Litoral 3 & PR & Galvão et al., 2002 & Parcelas, DAP $\geq 10 \mathrm{~cm}$ \\
\hline Matinhos & Litoral 4 & PR & Galvão et al., 2002 & Parcelas, DAP $\geq 10 \mathrm{~cm}$ \\
\hline Guaratuba & Litoral 5 & PR & Galvão et al., 2002 & Parcelas, DAP $\geq 10 \mathrm{~cm}$ \\
\hline Londrina & $\begin{array}{l}\text { Parque Municipal Arthur } \\
\text { Thomas }\end{array}$ & PR & Cotarelli et al., 2008 & Excursões \\
\hline Tibagi & Fazenda Batavo & PR & Dias et al., 1998 & Parcelas, DAP $\geq 5 \mathrm{~cm}$ \\
\hline Quatro Barras & Morro do Anhangava & PR & Portes et al., 2001 & Parcelas, DAP $\geq 10 \mathrm{~cm}$ \\
\hline $\begin{array}{l}\text { Cinco Montanhas na } \\
\text { Serra do Mar }\end{array}$ & - & PR & Koehler et al., 2002 & Parcelas, DAP $>10 \mathrm{~cm}$ \\
\hline Clevelândia & Clevelândia & PR & Valério et al., $2008 \mathrm{~b}$ & Parcelas, DAP $\geq 20 \mathrm{~cm}$ \\
\hline Tijucas do Sul & $\begin{array}{l}\text { Sistema Ecológico Vivat } \\
\text { Floresta }\end{array}$ & PR & Liebsch e Acra, 2004 & Parcelas, materiais férteis \\
\hline General Carneiro & $\begin{array}{l}\text { Faz. Indústrias Pedro N. } \\
\text { Pizzatto Ltda. }\end{array}$ & PR & Watzlawick et al., 2009 & Parcelas, DAP $>10 \mathrm{~cm}$ \\
\hline Palmeira & Três Morros & PR & Iurk, 2008 & Parcelas, fanerógamos férteis \\
\hline Piraquara & Mananciais da Serra & PR & $\begin{array}{l}\text { Reginato e Goldenberg, } \\
2007\end{array}$ & Parcelas, $\mathrm{PAP} \geq 10 \mathrm{~cm}$ \\
\hline Caçador & $\begin{array}{l}\text { Reserva } \\
\text { Embrapa-Epagri }\end{array}$ & $\mathrm{SC}$ & $\begin{array}{l}\text { Negrelle e Silva, } 1992 \\
\text { Lingner et al., } 2007\end{array}$ & $\begin{array}{l}\text { Quadrante e parcelas, } \\
D A P \geq 5 \mathrm{~cm} \text { e } C A P \geq 60 \mathrm{~cm}\end{array}$ \\
\hline Campo Belo do Sul & Capatazia Picassos & $\mathrm{SC}$ & Formento et al., 2004 & Parcelas, DAP $\geq 10 \mathrm{~cm}$ \\
\hline Bom Jardim da Serra & $\begin{array}{l}\text { Estâncias Ribeiro e } \\
\text { Machado }\end{array}$ & $\mathrm{SC}$ & Eskuche, 2007 & - \\
\hline Blumenau & $\begin{array}{l}\text { Parque Natural Nascentes do } \\
\text { Ribeirão Garcia }\end{array}$ & $\mathrm{SC}$ & Schorn e Galvão, 2006 & Parcelas, $\mathrm{PAP} \geq 15 \mathrm{~cm}$ \\
\hline $\begin{array}{l}\text { São Pedro de } \\
\text { Alcântara }\end{array}$ & - & $\mathrm{SC}$ & Mantovani et al., 2005 & Parcelas, DAP $\geq 5 \mathrm{~cm}$ \\
\hline Campos Novos & Ibicuí & $\mathrm{SC}$ & $\begin{array}{l}\text { Higuchi et al., dados não } \\
\text { publicados }\end{array}$ & Parcelas, DAP $\geq 5 \mathrm{~cm}$ \\
\hline Painel & Farofa & $\mathrm{SC}$ & $\begin{array}{l}\text { Higuchi et al., dados não } \\
\text { publicados }\end{array}$ & Parcelas, DAP $\geq 5 \mathrm{~cm}$ \\
\hline Itapoá & RPPN Volta Velha & $\mathrm{SC}$ & Negrelle, 2006 & Parcelas, variado \\
\hline
\end{tabular}


TABELA 1: Continuação ...

TABLE 1: Continued ...

\begin{tabular}{|c|c|c|c|c|}
\hline Município & Localidade & $\mathrm{E}$ & Autor(es) & M.A. e N.I \\
\hline Criciúma & $\begin{array}{l}\text { Parque Ecológico Municipal } \\
\text { José Milanese }\end{array}$ & $\mathrm{SC}$ & Silva, 2006 & Parcelas, DAP $\geq 5 \mathrm{~cm}$ \\
\hline Itapiranga & - & $\mathrm{SC}$ & Ruschel et al. 2003 & - \\
\hline Descanso & - & $\mathrm{SC}$ & Ruschel et al., 2003 & - \\
\hline Lages & Guará & $\mathrm{SC}$ & $\begin{array}{l}\text { Silva et al., dados não } \\
\text { publicados }\end{array}$ & Parcelas, DAP $\geq 5 \mathrm{~cm}$ \\
\hline Urubici & Serra do Corvo Branco & $\mathrm{SC}$ & Falkenberg, 2003 & Excursões, fanerógamos férteis \\
\hline Urubici & Morro da Igreja & $\mathrm{SC}$ & Falkenberg, 2003 & Excursões, fanerógamos férteis \\
\hline Bom Jardim da Serra & Serra do Rio do Rastro & $\mathrm{SC}$ & Falkenberg, 2003 & Excursões, fanerógamos férteis \\
\hline $\begin{array}{l}\text { São José dos } \\
\text { Ausentes }\end{array}$ & Serra da Rocinha & $\mathrm{RS}$ & Falkenberg, 2003 & Excursões, fanerógamos férteis \\
\hline Nova Prata & Fazenda Tupi & $\mathrm{RS}$ & Nascimento et al., 2001 & Parcelas, DAP $\geq 9,6 \mathrm{~cm}$ \\
\hline Camaquã & Água Grande & $\mathrm{RS}$ & Jurinitz e Jarenkow, 2003 & Parcelas, DAP $\geq 5 \mathrm{~cm}$ \\
\hline Santa Maria & Arroio Passo das Tropas & $\mathrm{RS}$ & Budke et al., 2004 & Parcelas, $\mathrm{PAP} \geq 15 \mathrm{~cm}$ \\
\hline Barra do Ribeiro & - & $\mathrm{RS}$ & Bergamin e Mondin, 2006 & Caminhamento, DAP $\geq 5 \mathrm{~cm}$ \\
\hline Frederico Westphalen & & $\mathrm{RS}$ & Martinazzo et al., 2004 & - \\
\hline- & Bacia do Rio Jacuí & $\mathrm{RS}$ & Lindenmaier e Budke, 2006 & Parcelas, $\mathrm{PAP} \geq 15 \mathrm{~cm}$ \\
\hline Porto Alegre & Bacia o Rio Gravataí & $\mathrm{RS}$ & Oliveira et al., 2005 & Caminhamentos \\
\hline Pelotas & Balneário da Praia do Laranjal & $\mathrm{RS}$ & Venzke et al., 2005 & Expedições \\
\hline $\begin{array}{l}\text { São Francisco de } \\
\text { Paula }\end{array}$ & $\begin{array}{l}\text { Floresta Nacional de São } \\
\text { Francisco de Paula }\end{array}$ & $\mathrm{RS}$ & $\begin{array}{l}\text { Rosário, 2001; Narvaes et } \\
\text { al., 2005; Duarte et al., } 2006\end{array}$ & $\begin{array}{l}\text { Parcelas, altura } \geq 2 \mathrm{~m}, \\
\mathrm{PAP} \geq 62,8 \mathrm{~cm}, \mathrm{CAP} \geq 3 \mathrm{~cm}, \\
\mathrm{DAP} \geq 5 \mathrm{~cm}\end{array}$ \\
\hline Santa Rosa & - & $\mathrm{RS}$ & Vaccaro e Longhi, 1995 & Parcelas, $\mathrm{PAP} \geq 30 \mathrm{~cm}$ \\
\hline Bom Jesus & Rio Pelotas & $\mathrm{RS}$ & Brack et al., 2009 & Caminhamento \\
\hline Caxias do Sul & Caxias do Sul & $\mathrm{RS}$ & Ramos e Boldo, 2007 & Parcelas \\
\hline Jaguari & São Roque & $\mathrm{RS}$ & Hack et al., 2005 & Parcelas, $\mathrm{PAP} \geq 30 \mathrm{~cm}$ \\
\hline Santiago & Carvori e Tupantuba & $\mathrm{RS}$ & Longhi, 1991 & Parcelas, $\mathrm{PAP} \geq 30 \mathrm{~cm}$ \\
\hline São Sepé & Fazenda Vista Alegre & $\mathrm{RS}$ & Longhi et al., 1992 & Parcelas, DAP $\geq 10 \mathrm{~cm}$ \\
\hline Vale do Sol & Linha XV de novembro & $\mathrm{RS}$ & Jarenkow e Waechter, 2001 & Parcelas, DAP $\geq 5 \mathrm{~cm}$ \\
\hline Vacaria & Refugiados & $\mathrm{RS}$ & Mauhs e Backes, 2002 & Parcelas, altura $\geq 0,5 \mathrm{~m}$ \\
\hline Santa Tereza & - & $\mathrm{RS}$ & Vaccaro et al., 1999 & Parcelas, $\mathrm{PAP} \geq 10 \mathrm{~cm}$ \\
\hline Criúva & Criúva & $\mathrm{RS}$ & Rondon Neto et al., $2002 \mathrm{~b}$ & Parcelas, DAP $\geq 5 \mathrm{~cm}$ \\
\hline
\end{tabular}

Em que: $\mathrm{E}=$ estado; M.A. = método de amostragem; N.I. = nível de inclusão; DAP = diâmetro a altura do peito, medido a 1,30 $\mathrm{m}$ do solo; $\mathrm{CAP}=$ circunferência a altura do peito; $\mathrm{PAP}=$ perímetro a altura do peito.

frio (b6), amplitude térmica anual (b7), temperatura média no trimestre mais úmido (b8), temperatura no trimestre mais úmido (b9), temperatura média no trimestre mais quente (b10), temperatura média no trimestre mais frio (b11), precipitação total anual (b12), precipitação no mês mais úmido (b13), precipitação no mês mais seco (b14), sazonalidade da precipitação (b15), precipitação no trimestre mais úmido (b16), precipitação no trimestre mais seco (b17), precipitação no trimestre mais quente (b18) e precipitação no trimestre mais frio (b19).
As informações das 58 áreas foram inseridas em uma planilha eletrônica, com o propósito de produzir duas matrizes: a primeira de dados de presença e ausência das espécies nos remanescentes e a segunda de informações geográficas e bioclimáticas de cada área.

\section{Análise dos Dados}

O número de espécies compartilhadas e exclusivas de cada fisionomia florestal estudada 


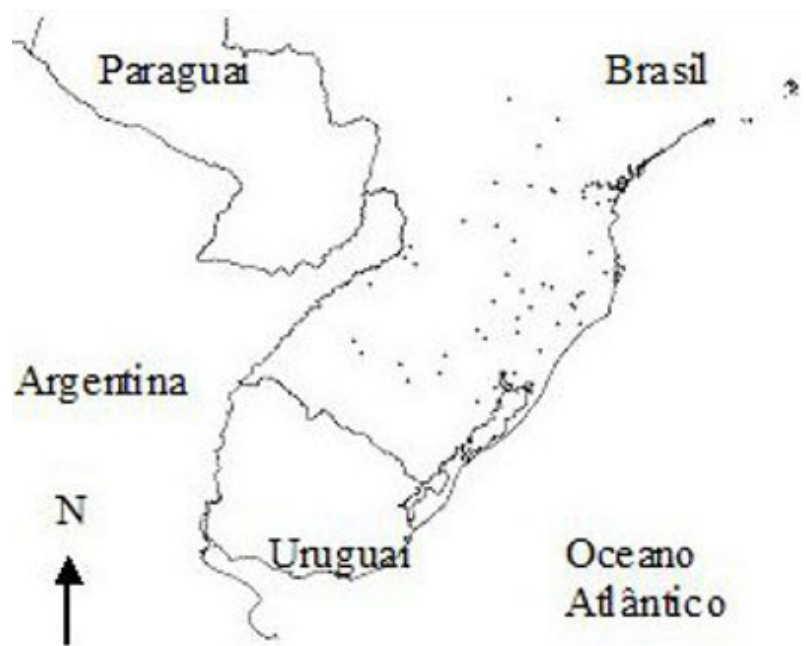

FIGURA 1: Localização das 58 áreas de florestas da Região Sul do Brasil, pertencentes a diferentes fisionomias utilizadas nas análises florísticas.

FIGURE 1: Location of the 58 forest areas in southern Brazil, belonging to different physiognomies used in floristic analysis.

foi demonstrado por meio um diagrama de Venn. Devido ao pequeno número de áreas pertencentes à Floresta Estacional Semidecidual (FESD), estas foram agrupadas juntamente com as áreas de Floresta Estacional Decidual (FED). Como cada fisionomia apresenta número de áreas amostradas diferente, a riqueza florística entre elas foi comparada padronizando para um mesmo número de áreas.

Com o propósito de encontrar padrões florísticos definidos apenas pelas espécies, foi realizada uma Análise de Correspondência Retificada (DCA), processada por meio do programa estatístico R (R DEVELOPMENT CORE TEAM, 2011), junto com a biblioteca Vegan (OKSANEN et al., 2009). Como destacado por Oliveira-Filho et al. (2005b), a escolha da DCA permite a definição de padrões ditados apenas pelas espécies, sem a influência de variáveis ambientais, como ocorre na Análise de Correspondência Canônica (CCA). A altitude e as variáveis bioclimáticas foram ajustadas e inseridas em forma de vetores a posteriori à ordenação produzida pela DCA, por meio da função envfit, da biblioteca Vegan, sendo que as variáveis de baixa significância $(p<0,001)$ e as redundantes foram excluídas da análise.

Com o objetivo de explorar e modelar a relação florística entre as áreas em função da hetero- geneidade climática existente foi empregado a análise de Árvore de Regressão Multivariada (ARM), realizada por meio do programa estatístico $\mathrm{R}(\mathrm{R}$ DEVELOPMENT CORE TEAM, 2011), utilizando a biblioteca mvpart (DE'ATH, 2006). Essa técnica particiona a comunidade arbórea em setores mais homogêneos baseando-se na similaridade florística entre as áreas, calculada pelo método de Sorensen, e nas variáveis ambientais associadas. Além disso, as variáveis significativas e seus respectivos valores limites (threshold values) são fornecidos para cada partição da comunidade, determinando onde cada área ocorre ao longo do gradiente ambiental (DE'ATH, 2006). Para cada setor definido pela árvore de regressão, foram verificadas quais eram as espécies mais frequentes.

\section{RESULTADOS}

Em termos absolutos, o número de espécies encontrado na FOM (409) foi superior ao encontrado na FOD (353) e nas Florestas Estacionais (318), mas isso ocorreu devido ao diferente número de áreas amostradas em cada fitofisionomia, que foi de 28, 15 e 15 áreas, respectivamente. Quando a comparação da riqueza é padronizada para um mesmo número de áreas (14), os valores de riqueza foram de $340,73 \pm 11,42 ; 320 \pm 27,08$ e $307,11 \pm 18,75$; respectivamente para FOD, FOM e FE.

A distribuição das espécies nas fitofisionomias pode ser observada no diagrama de Venn (Figura 2). Do total de espécies encontradas na FOM, 29,83\% (122) são exclusivas, 24,69\% (101) são compartilhadas apenas com as florestas estacionais (FE), 16,87\% (69) são compartilhadas apenas com a FOD e $28 \%$ (117) comuns a todas as formações analisadas. Para a FOM, a proporção de espécies endêmicas em relação as não endêmicas é de 0,43 . Do total de espécies encontradas na FOD, $38,24 \%$ (135) são exclusivas, apenas 9,07\% (32) são compartilhadas com as FE, 19,55\% (69) são compartilhadas apenas com a FOM e 33,14\% (117) comum a todas as formações analisadas. A proporção de endêmicas/não endêmicas na FOD foi de 0,62 . Do total de espécie encontrada nas FE (318), $21,38 \%$ (68) são exclusivas, $10,06 \%$ (32) são compartilhadas somente com as FOD, 31,76\% (101) são compartilhadas apenas com a FOM e 36,79\% (117) comum a todas as formações analisadas. A proporção de endêmicas/não endêmicas nas FE foi de 0,27.

A DCA para as áreas pertencentes às quatro fitofisionomias estudadas (FOM, FED, FESD e 


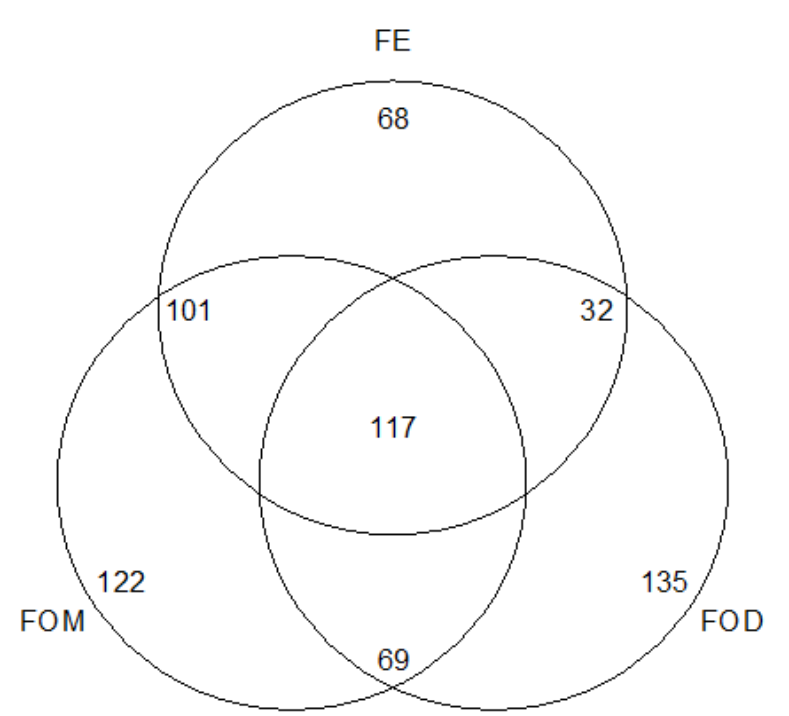

FIGURA 2: Diagrama de Venn construído a partir da listagem florística de 58 áreas da Região Sul do Brasil, considerando as fisionomias de Floresta Ombrófila Mista (FOM), Floresta Ombrófila Densa (FOD) e Floresta Estacional Decidual e Semidecidual (FE). Valores internos representam o número de espécies.

FIGURE 2: Venn diagram constructed from the floristic list of 58 areas of southern Brazil, considering the Araucaria Forest (FOM), Rain Forest (FOD) and Deciduous and Semidecidual Forests (FE) physiognomies. Internal values represent the number of species.

FOD) (Figura 3) obteve autovalores para o primeiro e segundo eixos 0,49 e 0,25, respectivamente. Em um extremo do diagrama, situadas no lado direito do eixo de ordenação, estão concentradas a maior parte das áreas de FOD, que é caracterizada por menor altitude (alt) e maior temperatura média no trimestre mais úmido (b8) e maiores temperaturas mínimas no mês mais frio (b6). No outro extremo, no lado esquerdo do diagrama, predominantemente no quadrante superior esquerdo, estão as áreas de maiores altitudes e menores temperaturas (b6, b1, b9 e b5) no presente estudo, representadas por formações alto-montanas de FOM (Serra Geral) e de FOD (Serra do Mar do Paraná).

As áreas com Floresta Decidual ocorreram nos quadrantes inferiores, estando positivamente associadas com a amplitude térmica anual (b7) e diária (b2) e a sazonalidade térmica (b4). No centro dos eixos de ordenação estão as áreas que podem ser consideradas como sendo de transição entre as diferentes fisionomias, como as Florestas Estacionais Semideciduais e algumas áreas de Floresta com Araucária e de Florestas Estacionais Deciduais.

O primeiro eixo de ordenação da DCA apresentou forte correlação com a temperatura média do trimestre mais úmido (b8), com a temperatura mínima no mês mais frio (b6), com a altitude (alt), com a temperatura média anual (b1) e com a temperatura média do mês mais seco (b9) (Tabela 2). O vetor que representa a altitude aponta para o lado oposto dos vetores que representam as variáveis de temperatura (b6, b1, b9, b5 e b4), indicando a existência de correlação negativa entre elas $(p<0,001$ pelo teste de associação entre variáveis). O eixo 2 esteve mais correlacionado com as variáveis amplitude térmica anual (b7) e diária (b2) e sazonalidade térmica (b4) (Tabela 2).

A Árvore de Regressão Multivariada (ARM) (Figura 4), explicando 0,52 da variação encontrada, discriminou quatro agrupamentos florísticos em função da similaridade entre as áreas e de acordo com as seguintes variáveis ambientais: precipitação no trimestre mais quente (b18), temperatura média anual (b1) e altitude. O primeiro grupo, que é também o mais distinto do restante, corresponde às áreas com precipitação no trimestre mais quente superior ou igual a $590 \mathrm{~mm}$. Neste agrupamento, concentraram-se as áreas pertencentes à Floresta Ombrófila Densa Baixo-Montana, Montana e Alto-Montana do Paraná, Litoral 1, Litoral 2, Litoral 3, Litoral 4, Morretes, Piraquara e Serra do Mar, e de Santa Catarina, Itapoá e São Pedro de Alcântara. As espécies mais frequentes nesse grupo foram: Alchornea glandulosa Poepp. \& Endl., Clusia criuva Cambess., entre outras (Tabela 3). O segundo agrupamento ocorreu nas áreas com precipitação no trimestre mais quente menor do que $590 \mathrm{~mm}$ e com temperatura média anual menor do que $15,15^{\circ} \mathrm{C}$, formado pelas áreas de Floresta Ombrófila Mista Alto-Montana da Serra Geral. As espécies mais frequentes nesse grupo foram: Ocotea pulchella Mart., Prunus myrtifolia (L.) Urb., dentre outras. A última partição, nas áreas onde a precipitação no trimestre mais quente é menor do que $590 \mathrm{~mm}$ e a temperatura média anual é maior ou igual a $15,15^{\circ} \mathrm{C}$, ocorreu em função da altitude e definiu os agrupamentos mais semelhantes entre si. O grupo das áreas que ocorrem em uma altitude superior ou igual a $780 \mathrm{~m}$ foi formado por áreas de Floresta Ombrófila Mista. As espécies mais 


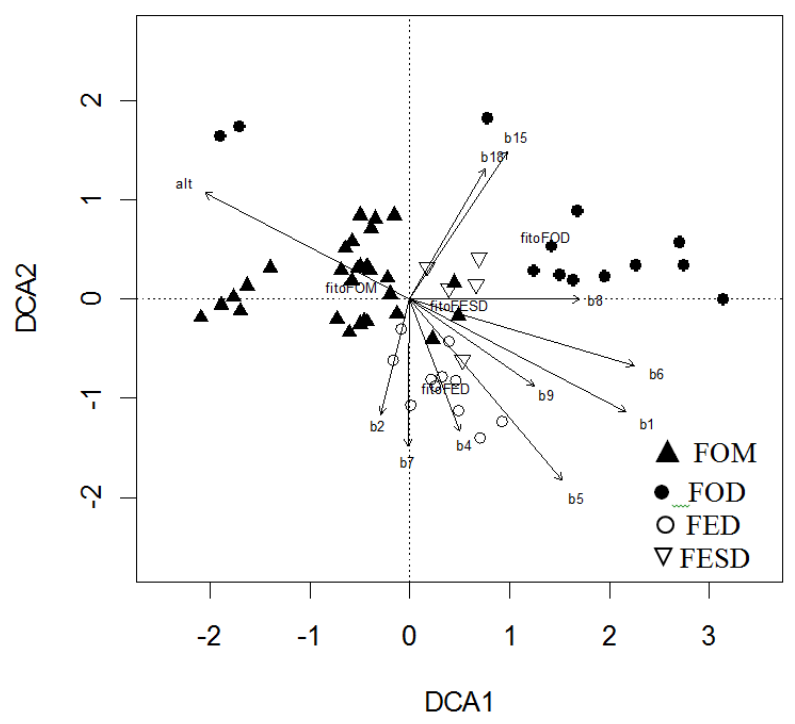

FIGURA 3: Diagrama de ordenação produzido pela Análise de Correspondência Retificada (DCA) para áreas florestais na Região Sul do Brasil. FOM: Floresta Ombrófila Mista, FOD: Floresta Ombrófila Densa, FED: Floresta Estacional Decidual e FESD: Floresta Estacional Semidecidual. Vetores: alt: Altitude, b1: Temperatura média anual, b2: Amplitude da temperatura média diária, b4: Sazonalidade térmica, b5: Temperatura máxima no mês mais quente, b6: Temperatura mínima no mês mais frio, b7: Amplitude térmica anual, b8: Temperatura média do trimestre mais úmido, b9: Temperatura média do mês mais seco, b15: Sazonalidade de precipitação, b18: precipitação no trimestre mais quente.

FIGURE 3: Ordination diagram produced by Detrended Correspondence Analysis (DCA) for forest areas in southern Brazil. FOM: Araucaria forest, FOD: Rain forest, EDF: Deciduous forest and FESD: Semi-deciduous forest. Vectors: Alt: altitude, b1: Annual mean temperature, b2: Mean diurnal range (Mean of monthly ( $\max$ temp - min temp), b4: Temperature seasonality (standard deviation*100), b5: Maximum temperature of the warmest month, b6: Minimum temperature of the coldest month, b7: Temperature annual range (b5-b6), b8: Mean temperature of the wettest quarter, b9: Mean temperature of the driest quarter, b15: Precipitation seasonality (Coefficient of Variation), b18: Precipitation of the warmest quarter.

TABELA 2: Significância ( $p$ ) das variáveis ambientais em relação aos eixos de ordenação produzido pela Análise de Correspondência Retificada (DCA) para 58 áreas florestais na Região Sul do Brasil. Valores estimados baseando-se em 1000 permutações.

TABLE 2: Significance $(p)$ of environmental variables in relation to ordination axes produced by Rectified Correspondence Analysis (DCA), for 58 forest areas in southern Brazil. Estimated values based on 1000 permutations.

\begin{tabular}{lcccc}
\hline \multirow{2}{*}{ Variáveis bioclimáticas } & \multicolumn{2}{c}{ Eixos da DCA } & \multirow{2}{*}{$\mathrm{R}^{2}$} & $p$ \\
\cline { 2 - 3 } & DCA 1 & DCA 2 & & $0,0,6071$ \\
Altitude (m) & $-0,89$ & 0,46 & $\mathbf{0 , 6 0 7 1}$ & 0,001 \\
b1 - Temperatura média anual & 0,89 & $-0,46$ & $\mathbf{0 , 6 8 0 0}$ & 0,001 \\
b2 - Amplitude da temperatura média diária & $-0,24$ & $-0,97$ & 0,1606 & 0,006 \\
b4 - Sazonalidade térmica & 0,35 & $-0,94$ & 0,2296 & 0,001 \\
b5 - Temperatura máxima no mês mais quente & 0,64 & $-0,77$ & $\mathbf{0 , 6 3 5 5}$ & 0,001 \\
b6 - Temperatura mínima no mês mais frio & 0,96 & $-0,28$ & $\mathbf{0 , 6 2 3 8}$ & 0,001 \\
b7 - Amplitude térmica anual & $-0,01$ & $-0,10$ & 0,2489 & 0,001 \\
b8 - Temperatura média do trimestre mais úmidos & 1,00 & 0,001 & 0,3271 & 0,001 \\
b9 - Temperatura média do mês mais seco & 0,82 & $-0,57$ & 0,2628 & 0,001 \\
b15 - Sazonalidade de precipitação & 0,55 & 0,84 & 0,3567 & 0,001 \\
b18 - Precipitação no trimestre mais quente & 0,51 & 0,86 & 0,2596 & 0,001 \\
\hline
\end{tabular}




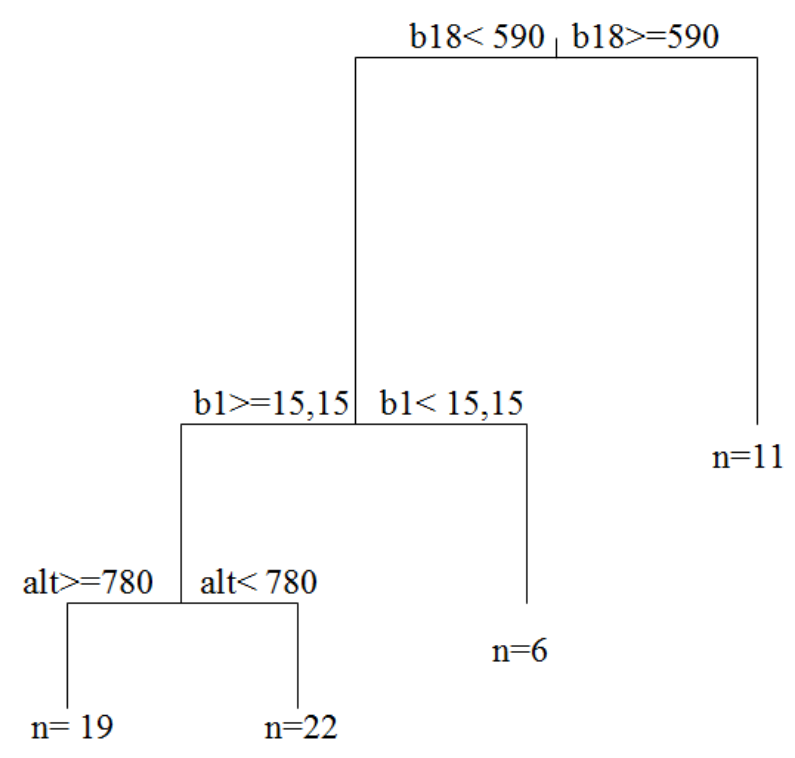

Erro : 0,424

FIGURA 4: Árvore de Regressão Multivariada (ARM) realizada para a matriz de similaridade entre as áreas de florestas analisadas na Região Sul do Brasil, em função da heterogeneidade ambiental existente (altitude e bioclima). No final de cada ramificação está indicado o número de áreas (n) que se enquadraram em cada condição ambiental.

FIGURE 4: Multivariate Regression Tree (ARM) produced considering the similarity matrix between the studied forest areas in southern Brazil, in function of the environmental heterogeneity (altitude and climate). The end of each branch shows the number of areas (n) that were placed in each environmental condition.

frequentes para esse agrupamento foram: Araucaria angustifolia (Bertol.) O. Kuntze, Alophyllus edulis (A.St.-Hil., Cambess. \&A.Juss.) Radlk., entre outras. O agrupamento com altitude menor do que $780 \mathrm{~m}$ foi formado, predominantemente, por áreas de Florestas Estacionais. Também ficaram neste último grupo as áreas de FOM com forte influência de contingentes das Florestas Estacionais, como Campos Novos, Arapoti e Tibagi, e as FOD que não apresentam elevada precipitação no trimestre mais quente (Blumenau e Criciúma, em SC). As espé- cies mais frequentes neste grupo foram: A. edulis, Casearia sylvestris Sw., etc.

\section{DISCUSSÃO}

Os resultados demonstraram, para as áreas analisadas na Região Sul do Brasil, a formação de agrupamentos florísticos, em resposta às variáveis ambientais (bioclimáticas e altitude) e em função da forma que se dá o fluxo de espécies por meio das rotas migratórias existentes. Foi possível observar, pelo diagrama de Venn e pelas análises da DCA e ARM, a maior afinidade florística entre a Floresta com Araucária (FOM) e as Florestas Estacionais (FE), sendo que isso ocorre porque, entre essas duas formações florestais existe maior permeabilidade de espécies, devido à ausência de uma grande barreira geográfica e climática isolando-as, como acontece para a FOD.

Afastando-se do litoral em sentido ao interior, existe uma mudança abrupta na altitude, representada pelo "paredão" constituído pela encosta da Serra do Mar e Serra Geral, que forma uma barreira geográfica e bioclimática, devido, principalmente, às baixas temperaturas associadas às maiores altitudes. Essa barreira interfere no regime de chuva por meio da orografia, o que pode explicar a elevada precipitação concentrada durante o trimestre mais quente do ano na FOD, demonstrada pela ARM. Essas condições climáticas, junto com o isolamento geográfico, permitem o desenvolvimento da FOD, com a presença de várias espécies exclusivas e intolerantes a baixa temperatura, que não conseguem "subir a serra" e fazer a travessia para o oeste. Como destacado por Oliveira-Filho e Fontes (2000), na Região Sudeste e Sul do Brasil, a ocorrência de geadas representa um importante fator limitante para a ocorrência de espécies, estando associada tanto com a altitude, quanto com a latitude.

Ao longo desse acentuado gradiente altitudinal e de temperatura, ocorre uma considerável substituição de espécies, de forma que as áreas alto-montanas (Serra Geral e Serra do Mar do Paraná), com espécies tolerantes a baixa temperatura, e as áreas que ocorrem nas planícies litorâneas, com espécies megatérmicas, ocuparam extremos opostos no eixo 1 do diagrama de ordenação (Figura $3)$. O elevado autovalor do eixo $1(>0,3)$ confirma esse resultado de alta substituição de espécies (TER BRAAK, 1995) em contraste com o menor autovalor do eixo $2(0,25)$, que indica um gradiente ambiental mais curto e menor substituição de espécies. 
TABELA 3: Espécies arbóreas com maior frequência em cada setor definido pela Árvore de Regressão Multivariada para as áreas de floresta pertencentes a diferentes fitofisionomias da Região Sul do Brasil.

TABLE 3: Most frequent tree species in each sector defined by Multivariate Regression Tree for the forest areas belonging to different vegetation types in southern Brazil.

\begin{tabular}{|c|c|c|}
\hline Divisão da ARM & Espécies & Freq(\%) \\
\hline \multirow{10}{*}{$\begin{array}{l}\text { Divisão } 1 \\
\text { b18 } \geq 590 \mathrm{~mm}\end{array}$} & Alchornea glandulosa Poepp. \& Endl. & 64 \\
\hline & Clusia criuva Cambess. & 64 \\
\hline & Ilex dumosa Reissek & 55 \\
\hline & Ficus luschnathiana (Miq.) Miq. & 45 \\
\hline & Calypthrantes lucida Mart. ex DC. & 45 \\
\hline & Maytenus robusta Reissek & 45 \\
\hline & Andira anthelmia(Vell.) J.F. Macbr. & 45 \\
\hline & Calophyllum brasiliense Cambess. & 45 \\
\hline & Tabebuia cassinoides DC. & 45 \\
\hline & Ocotea pulchella Mart. & 36 \\
\hline \multirow{10}{*}{$\begin{array}{l}\text { Divisão } 2 \\
\text { b1 }<15,15^{\circ} \mathrm{C}\end{array}$} & Ocotea pulchella (Nees) Mez & 100 \\
\hline & Prunus myrtifolia (L.) Urb. & 100 \\
\hline & Dasyphyllum brasiliense (Spreng.) Cabrera & 100 \\
\hline & Dicksonia sellowiana Hook. & 100 \\
\hline & Rhamnus sphaerosperma $\mathrm{Sw}$. & 100 \\
\hline & Araucaria angustifolia (Bertol.) Kuntze & 100 \\
\hline & Solanum sanctaecatharinae Dunal & 100 \\
\hline & Berberis laurina Billb. & 100 \\
\hline & Myrceugenia oxysepala(Burret) D.Legrand \& Kausel & 100 \\
\hline & Mimosa scabrella Benth. & 100 \\
\hline \multirow{8}{*}{$\begin{array}{l}\text { Divisão } 3 \\
\text { Alt } \geq 780 \text { m }\end{array}$} & Araucaria angustifolia (Bertol.) O.Kuntze & 89 \\
\hline & Allophylus edulis (A.St.-Hil., Cambess. \&A.Juss.) Radlk. & 89 \\
\hline & Matayba elaeagnoides Radlk. & 89 \\
\hline & Casearia decandra Jacq. & 84 \\
\hline & Cupania vernalis Cambess. & 84 \\
\hline & Gymnanthes concolor (Spreng.) Müll.Arg. & 84 \\
\hline & Solanum granulosoleprosum Dunal & 74 \\
\hline & Vernonanthura discolor (Spreng.) H.Rob. & 74 \\
\hline \multirow{10}{*}{ Alt $<780 \mathrm{~m}$} & Allophylus edulis (A.St.-Hil., Cambess. \&A.Juss.) Radlk. & 91 \\
\hline & Casearia sylvestris $\mathrm{Sw}$. & 86 \\
\hline & Cupania vernalis Cambess. & 82 \\
\hline & Luehea divaricata Mart. & 82 \\
\hline & Cabralea canjerana (Vell.) Mart. & 77 \\
\hline & Cedrella fissilis Vell. & 73 \\
\hline & Nectandra megapotamica (Spreng.) Mez & 73 \\
\hline & Sorocea bonplandii (Baill.) W.C.Burger et al. & 73 \\
\hline & Matayba elaeagnoides Radlk. & 68 \\
\hline & Campomanesia xanthocarpa O.Berg & 68 \\
\hline
\end{tabular}


Rumando no sentido sul ao longo da faixa litorânea, a FOD cede espaço às Florestas Estacionais, à medida que se tem a redução da temperatura, associada ao aumento da latitude e redução da precipitação durante o trimestre mais quente, que, supostamente, pode estar associada à diminuição de chuvas orográficas, causada pelo desaparecimento da serra litorânea, na proximidade de Osório, no litoral norte gaúcho. Entretanto, várias espécies de origem atlântica tolerantes a essas novas condições ambientais conseguem se desenvolver, misturando-se ao elemento decíduo. O fato da Floresta Estacional Semidecidual que ocorre no Rio Grande do Sul apresentar certa similaridade florística com as áreas de FOD, particularmente em Criciúma, na Planície litorânea do Sul de Santa Catarina, pode ser explicado devido às áreas analisadas de FESD ocorrem num local de "encontro" entre o elemento florístico típico da rota migratória do Leste (Atlântico) com aquele da rota migratória do Oeste (Bacia Paraná-Uruguai).

A FED formada a partir da chegada de elementos deciduais das bacias dos Rios Paraná e Uruguai ocorrem nos locais associados com elevada amplitude térmica anual (b7) e diária (b2), sazonalidade térmica (b4) e elevada temperatura máxima no mês mais quente (b5). Diferentemente das florestas estacionais tropicais, que apresentam a deciduidade associada a uma estação de baixa precipitação pluviométrica, as subtropicais da região sul apresentam deciduidade provavelmente associada com variações térmicas e de fotoperíodo (ATHAYDE et al., 2009). Estes resultados reforçam a hipótese levantada por Lindenmaier e Budke (2006) de que a pluviosidade não é um fator restritivo à distribuição geográfica das espécies na região central do Rio Grande do Sul por não ocorrerem períodos sistematicamente secos. Por outro lado, a variação da temperatura e do fotoperíodo que ocorre na região requerem grande plasticidade ecológica das espécies, uma vez que o limite entre mínimas e máximas absolutas para a região é superior a $40^{\circ} \mathrm{C}$ (LINDENMAIER e BUDKE, 2006).

Nas áreas com altitudes superiores a $780 \mathrm{~m}$, cobrindo as bacias hidrográficas dos rios que deságuam nos Rios Uruguai e Paraguai, seguindo um suave declive no sentido para o interior, ocorre a maior extensão territorial ocupada pela Floresta Ombrófila Mista. Essas condições topográficas favorecem maior contato com as Florestas Estacionais que ocorrem nas mesmas bacias hidrográficas, resultando em um maior fluxo de espécies entre elas e maior similaridade florística. Isto ficou demonstrado no diagrama de Venn, pelo maior número de espécies compartilhadas, na DCA, pelo maior agrupamento e baixa substituição de espécies ao longo do eixo 2, em que se deu a separação dessas fitofisionomias, e pela ARM, onde essas foram agrupadas nos locais com temperatura média anual maior do que $15,15^{\circ} \mathrm{C}$. Conforme já analisado por Jarenkow e Budke (2010), as áreas de Floresta Ombrófila Mista, em sua porção mais ao oeste, acabam por se mesclarem com as Florestas estacionais, de forma que em certas áreas, a similaridade florística acaba sendo maior entre remanescentes de Floresta Estacional e FOM do que entre remanescentes de Floresta com Araucária. Estes autores revelaram que a Floresta Ombrófila Mista possui no mínimo três setores ou porções geográficas de distribuição: uma formada pelas áreas situadas entre Campos do Jordão e Visconde de Mauá (limite norte de distribuição); uma segunda área que abrange vasta extensão dos segundo e terceiro planaltos paranaenses e norte de Santa Catarina e por fim, um terceiro setor, que inclui as áreas ao sul de Santa Catarina e Rio Grande do Sul, os quais possuem o maior número de espécies de ampla distribuição e, portanto, onde já se percebe uma diluição em termos de riqueza de espécies, dentro da área de distribuição da Floresta Ombrófila Mista (JARENKOW e BUDKE, 2010).

\section{CONCLUSÕES}

As hipóteses de que (i) existe maior similaridade entre FOM e Florestas Estacionais e de que (ii) o componente arbóreo das florestas sul-brasileiras apresenta variações florísticas e fisionômicas devido à heterogeneidade bioclimática existente foram aceitas.

Considerando um cenário de mudanças climáticas futuras, provocadas pela emissão de gases do efeito estufa, as áreas alto-montanas com baixa temperatura média anual podem ser consideradas como sendo as mais sensíveis do ponto de vista ecológico. $\mathrm{O}$ aumento de $1{ }^{\circ} \mathrm{C}$ será suficiente para algumas áreas, como a Serra da Rocinha e Painel, passarem do limiar de $15,15^{\circ} \mathrm{C}$, que caracteriza climaticamente estas áreas. Com isso, algumas espécies exclusivas poderão se extinguir localmente, ou passarem a ocupar microssítios favoráveis. Da mesma forma, algumas espécies que ocorrem em áreas mais baixas irão migrar para áreas de maior altitude, para compensar o acréscimo de temperatura, por meio do ajuste do nicho termal. Ao longo da história 
evolutiva da Região Sul do Brasil, as florestas ribeirinhas e fragmentos florestais naturais vêm servindo para esse propósito, como corredor de migração e stepping stones, o que justifica a sua manutenção e proteção.

Destaca-se ainda a necessidade de uma melhor caracterização florística de regiões pouco estudadas, principalmente no Estado de Santa Catarina, e de estudos sobre a diversidade genética de populações de espécies arbóreas. A caracterização florística de áreas pouco estudadas, como áreas de transição entre FOM e FOD, permitirão um maior refinamento sobre os padrões fitogeográficos da região. Já estudos genéticos, como demonstrado por Carnaval et al. (2009), permitirão a verificação da expansão populacional em áreas climaticamente instáveis, de colonização recente, a partir de refúgios climaticamente estáveis.

\section{REFERÊNCIAS BIBLIOGRÁFICAS}

ATHAYDE, E. A. et al. Fenologia de espécies arbóreas em uma floresta ribeirinha em Santa Maria, sul do Brasil. Revista Brasileira de Biociências, Porto Alegre, v. 7, n. 1, p. 43-51. 2009.

BARDDAL, M. et al. Fitossociologia do subbosque de uma Floresta Ombrófila Mista Aluvial, no município de Araucária, PR. Ciência Florestal, Santa Maria, v. 14, n. 1, p. 35-45. 2004.

BEHLING, H. Late Quaternary vegetation, climate and fire history of the Araucaria forest and campos region from Serra Campos Gerais, Paraná State (South Brazil). Review of Palaeobotany and Palynology, v. 97, n. 1-2, p.109-121. 1997.

BEHLING, $\mathrm{H}$. et al. Late quaternary Araucaria forest, grassland (Campos), fire and climate dynamics, studied by high-resolution pollen, charcoal and multivariate analysis of the Cambará do Sul core in southern Brazil. Palaeogeography, Palaeoclimatology, Palaeoecology, v. 203, n. 3-4, p. 277-297. 2004.

BEHLING, H.; PILLAR, V. Late Quaternary vegetation, biodiversity and fire dynamics on the southern Brazilian highland and their implication for conservation and management of modern Araucaria forest and grassland ecosystems. Philosophical Transactions of the Royal Society B: Biological Sciences, v. 362, n. 1478, p. 243-251. 2007.

BERGAMIN, R.; MONDIN, C. Composição florística e relações fitogeográficas do componente arbóreo de um fragmento florestal no município de Barra do Ribeiro, Rio Grande do Sul, Brasil.
Pesquisas, série Botânica, São Leopoldo, v. 57, p. 217-229. 2006.

BLUM, C. T. et al.Caracterização florística e ecológica de remanescentes florestais no Rio das Cinzas, Norte Pioneiro, PR. In: SEMINÁRIO NACIONAL DE DEGRADAÇÃO E RECUPERAÇÃO AMBIENTAL, 2003, Foz do Iguaçu.. Anais...Foz do Iguaçu: SOBRADE, 2003. BRACK, P. et al. Levantamento preliminar da flora e da vegetação do vale do rio Pelotas, no município de Bom Jesus, RS, e a importância de sua conservação. INGA Estudo Ambientais, Relatório Técnico. 2009.

BUDKE, J.C. et al. Florística e fitossociologia do componente arbóreo de uma floresta ribeirinha, arroio Passo das Tropas, Santa Maria, RS, Brasil. Acta Botanica Brasilica, Feira de Santana, v. 18, n. 3, p. 581-589. 2004.

CARNAVAL, A. et al. Stability predicts genetic diversity in the Brazilian Atlantic Forest hotspot. Science, v. 323, n. 5915, p. 785-789. 2009.

COTARELli, V. M. et al. Florística do Parque Municipal Arthur Thomas, Londrina, Paraná, Brasil. Acta Biológica Paranaense, Curitiba, v. 37, n. 1-2, p. 123-146. 2008.

DE'ATH, G. mvpart: Multivariate partitioning. R package version, v. 1, n. 2-4. 2006.

DIAS, M. et al. Composição florística e fitossociologia do componente arbóreo das florestas ciliares do rio Iapó, na bacia do rio Tibagi, Tibagi, PR. Revista Brasileira de Botânica, São Paulo, v. 21, n. 2, p. 183-195. 1998.

DUARTE, L. et al.What saplings can tell us about forest expansion over natural grasslands. Journal of Vegetation Science, v. 17, n. 6, p. 799-808. 2006. ESKUCHE, U. El bosque de Araucaria con Podocarpus y los campos de Bom Jardim da Serra, Santa Catarina (Brasil meridional). Boletín de la Sociedad Argentina de Botánica, Córdoba, v. 42, n. 3-4, p. 295-308. 2007.

FALKENBERG, D. Matinhas nebulares e vegetação rupícola dos Aparados da Serra Geral (SC/RS), sul do Brasil. 2003. 558 f. Tese (Doutorado em Biologia Vegetal) - Universidade Estadual de Campinas, Campinas, 2003.

FERNANDES, A. Conexões florísticas do Brasil. Fortaleza: Banco do Nordeste, 2003. 134 p.

FORMENTO, S. et al.Dinâmica estrutural arbórea de uma Floresta Ombrófila Mista em Campo Belo do Sul, SC. Cerne, Lavras, v. 10, n. 2, p. 196-212. 2004.

GALVÃO, F. et al. Composição florística e 
fitossociologia de caxetais do litoral do estado do Paraná-Brasil. Floresta, Curitiba, v. 32, n. 1. p. 1739. 2002.

HACK, C. et al. Análise fitossociológica de um fragmento de Floresta Estacional Decidual no município de Jaguari, RS. Ciência Rural, Santa Maria, v. 35, n. 5, p. 1083-1091. 2005.

HIJMANS, R. et al. Very high resolution interpolated climate surfaces for global land areas. International Journal of Climatology, v. 25, n. 15,p. 1965-1978. 2005.

IBGE. Manual Técnico da Vegetação Brasileira. Manuais Técnicos em Geociências, 1992. v. 1.

IURK, M. C. Levantamento florístico de um fragmento de Floresta Ombrófila Mista Aluvial do Rio Iguaçu, município de Palmeira - PR. 2008. 102 f. Dissertação (Mestrado em Botânica) Universidade Federal do Paraná, Curitiba, 2008.

JARENKOW, J. A.; WAECHTER, J. Composição, estrutura e relações florísticas do componente arbóreo de uma floresta estacional no Rio Grande do Sul, Brasil. Revista Brasileira de Botânica, São Paulo, v. 24, n. 3, p. 263-272. 2001.

JARENKOW, J. A.; BUDKE, J.C. Padrões florísticos e análise estrutural de remanescentes florestais com Araucaria angustifolia no Brasil. In: Floresta com Araucária: ecologia, conservação e desenvolvimento sustentável, FONSECA, C. S. D. et al., orgs.). Ribeirão Preto: Holos, 2010. p. 113126.

JURINITZ, C.; JARENKOW, J. A. Estrutura do componente arbóreo de uma floresta estacional na Serra do Sudeste, Rio Grande do Sul, Brasil. Revista Brasileira de Botânica, São Paulo, v. 26, n. 4, p. 475-487. 2003.

KAGEYAMA, P. et al. Recuperação de áreas ciliares. In: Matas Ciliares: conservação e recuperação RODRIGUES, R. R.; LEITÃO FILHO, H. L.,(eds.).São Paulo: Edusp, 2001. p.249-269.

KATAOKA-SILVA, A. M. Florística e efeito de borda em fragmentos da Floresta Ombrófila Mista na região de Guarapuava, PR. 2006. 91 f. Tese (Doutorado em Ecologia) - Universidade Federal de São Carlos, São Carlos, 2006.

KOEHLER, A. et al. Floresta Ombrófila Densa Altomontana: aspectos florísticos e estruturais de diferentes trechos na Serra do Mar, PR. Ciência Florestal, Santa Maria, v. 12, n. 2, p. 27-39. 2002.

KOZERA, C. et al. Fitossociologia do componente arbóreo de um fragmento de Floresta Ombrófila Mista Montana, Curitiba, PR, BR. Floresta, Curitiba, v. 36, n. 2, p. 225-237. 2006.
LAURANCE, W. Reflections on the tropical deforestation crisis. Biological Conservation, v. 91, n. 2-3, p. 109-117. 1999.

LEDRU, M. Late Quaternary environmental and climatic changes in central Brazil. Quaternary Research, v. 39, n. 1, p. 90-98. 1993.

LIEBSCH, D.; ACRA, L. Riqueza de espécies de sub-bosque de um fragmento de Floresta Ombrófila Mista em Tijucas do Sul, PR. Ciência Florestal, Santa Maria, v. 14, n. 1, p. 67-76. 2004.

LINDENMAIER, D. S.; BUDKE, J. C. Florística, diversidade e distribuição espacial das espécies arbóreas em uma floresta estacional na bacia do Rio Jacuí, Sul do Brasil.Pesquisas, série Botânica, São Leopoldo, v. 57, p. 193-216. 2006.

LINGNER, D. et al. Caracterização da estrutura e da dinâmica de um remanescente de Floresta com Araucária no Planalto Catarinense. Pesquisa Florestal Brasileira, Colombo, v. 55, p. 55-66. 2007.

LONGHI, S. Aspectos fitossociológicos dos "capões" na região de Carovi e Tupantuba, em Santiago, RS. Ciência Florestal, Santa Maria, v. 1, n. 1, p. 22-39. 1991.

LONGHI, S. et al. Composição florística e estrutura fitossociológica de um "Capão" de Podocarpus lambertii Klotz, no Rio Grande do Sul. Ciência Florestal, Santa Maria, v. 2, n. 1, p. 27-47. 1992.

MANTOVANI, M. et al. Diversidade de espécies e estrutura sucessional de uma formação secundária da Floresta Ombrófila Densa. Scientia forestalis, Piracicaba, v. 67, p. 14-26. 2005.

MARTINAZZO, E. G. et al.Estudo da flora de mata ciliar no município de Frederico Westphalen-RS. In: CONGRESSO BRASILEIRO DE SISTEMAS AGROFLORESTAIS, 5., 2004, Curitiba. Anais... Curitiba:EMBRAPA, 2004.

MAUHS, J.; BACKES, A. Estrutura fitossociológica e regeneração natural de um fragmento de Floresta Ombrófila Mista exposto a perturbações antrópicas. Pesquisas, Botânica, São Leopoldo,v. 52, p. 89109. 2002.

NARVAES, I. et al. Estrutura da regeneração natural em Floresta Ombrófila Mista na Floresta Nacional de São Francisco de Paula, RS. Ciência Florestal, Santa Maria, v. 15, n. 4, p. 331-342. 2005.

NASCIMENTO, A. et al. Estrutura e padrões de distribuição espacial de espécies arbóreas em uma amostra de Floresta Ombrófila Mista em Nova Prata, RS. Ciência Florestal, Santa Maria, v. 11, n. 1, p. 105-119. 2001.

NEGRELLE, R. Composição florística e estrutura 
vertical de um trecho de Floresta Ombrófila Densa de Planície Quaternária. Hoehnea, São Paulo, v. 33, n. 3, p. 261-289. 2006.

NEGRELLE, R.; SILVA, F. Fitossociologia de um trecho de floresta com Araucaria angustifolia (Bert.) O. Ktze. no município de Caçador-SC. Boletim de Pesquisa Florestal, Colombo, v. 24, n. 25, p. 37-54. 1992.

OKSANEN, J. et al.Vegan: community ecology package. $\mathbf{R}$ package version, 2009. v. 1, p. 8-8.

OLIVEIRA, M. L. A. A. et al. Levantamento florístico de fragmentos florestais na bacia hidrográfica do Rio Gravataí, Rio Grande do Sul, Brasil. Iheringia, sérieBotânica, Porto Alegre, v. 60, n. 2, p. 269-284. 2005.

OLIVEIRA-FILHO, A. T.; FONTES, M. A. L. Patterns of floristic differentiation among Atlantic forests in southeastern Brazil and the influence of climate. Biotropica, Lawrence, v. 32, n. 4, p. 793810. 2000.

OLIVEIRA-FILHO, A. T. et al.Floristic relationships of seasonally dry forests of Eastern South America based on tree species distribution patterns. In: Neotropical savannas and seasonally dry forests: plant diversity, biogeography and conservation. Boca Raton: CRC Press, 2005b. p.151-184.

PORTES, M. C. G. O. et al.Caracterização florística e estrutural de uma Floresta Ombrófila Densa Altomontana do Morro do Anhangava, Quatro Barras-PR. Floresta, Curitiba, v. 31, n. 1, p. 22-31. 2001.

R DEVELOPMENT CORE TEAM. R: A language and environment for statistical computing. R Foundation for Statistical Computing, 2008. Disponível em: $<$ (http://www.R-project.org)> Acesso em: 18 de fev. de 2011.

RAMBO, B. A imigração da selva higrófila no Rio Grande do Sul. Anais Botânicos do Herbário Barbosa Rodrigues, Itajaí, v. 3, n. 3, p. 55-91. 1951.

RAMOS, A. J. K.; BOLDO, E. Diversidade florística e aspectos fitossociológicos de formações florestais em estágio sucessional secundário na Floresta Ombrófila Mista, município de Caxias do Sul-RS. Revista Brasileira de Agroecologia, Cruz Alta, v. 2, n. 1, p. 111-116. 2007.

REGINATO, M.; GOLDENBERG, R. Análise florística, estrutural e fitogeográfica da vegetação em região de transição entre as Florestas Ombrófila Mista e Densa Montana, Piraquara, Paraná, Brasil.
Hoehnea, São Paulo, v. 34, n. 3, p. 349-364. 2007. RONDON NETO, R. et al. Caracterização florística e estrutural de um fragmento de Floresta Ombrófila Mista em Curitiba, PR, Brasil. Floresta, Curitiba, v. 32, n. 1, p. 3-16. 2002a.

RONDON NETO, R. et al.Análise florística e estrutural de um fragmento de Floresta Ombrófila Mista Montana, situado em Criúva, RS-Brasil. Ciência Florestal, Santa Maria, v. 12, n. 1, p. 2937. $2002 b$.

ROSÁRIO, D. Padrões florísticos e tipos funcionais em floresta com araucária e suas relações com o solo. 2001. 136 f. Dissertação (Mestrado em Ecologia) - Universidade Federal do Rio Grande do Sul, Porto Alegre 2001.

RUSCHEL, A. et al. Evolução do uso e valorização das espécies madeiráveis da Floresta Estacional Decidual do Alto-Uruguai, SC. Ciência Florestal, Santa Maria, v. 13, n. 1, p. 153-166. 2003.

SANQUETTA, C. et al. Dinâmica da composição florística de um fragmento de Floresta Ombrófila Mista no Centro-Sul do Paraná. Revista Ciências Exatas e Naturais, Guarapuava, v. 1, n. 2, p. 7788. 2000.

SCHORN, L.; GALVÃO, F. Dinâmica da regeneração natural em três estágios sucessionais de uma Floresta Ombrófila Densa em Blumenau, SC. Floresta, Curitiba, v. 36, n. 1, p. 59-73. 2006.

SEGER, C. et al. Levantamento florístico e análise fitossociológica de um remanescente de Floresta Ombrófila Mista localizado no município de Pinhais, Paraná-Brasil. Floresta, Curitiba, v. 35, n. 2, p. 291-302. 2005.

SILVA, F. Composição florística e estrutura fitossociológica da floresta tropical ombrófila da encosta Atlântica no município de Morretes, Estado do Paraná. Acta Biológica Paranaense, Curitiba, v. 23, n. 1-4, p. 1-54. 1994.

SILVA, R. T. Florística e estrutura da sinúsia arbórea de um fragmento urbano de Floresta Ombrófila Densa do Município de Criciúma, Santa Catarina. 2006. 61 f. Dissertação (Mestradoem Ciências Ambientais) - Universidade do Extremo Sul Catarinense, Criciúma, 2006.

TABARELLI, M. et al. Effects of habitat fragmentation on plant guild structure in the montane Atlantic forest of southeastern Brazil. Biological Conservation, v. 91, n. 2-3, p. 119-127. 1999.

TER BRAAK, C. J. F. Ordination. In: Data analysis in community and landscape ecology. JONGMAN, R. H. et al.. Cambridge: Cambridge 
University, 1995. p. 91-173.

VACCARO, S.; LONGHI, S. Análise fitossociológica de algumas áreas remanescentes da Floresta do Alto Uruguai entre os rios Ijuí e Turvo, no Rio Grande do Sul. Ciência Florestal, Santa Maria,v. 5,n. 1,p. 33-53. 1995.

VACCARO, S. et al. Aspectos da composição florística e categorias sucessionais do estrato arbóreo de três subseres de uma floresta estacional decidual, no município de Santa Tereza-RS. Ciência Florestal, Santa Maria, v. 9, n. 1, p. 1-18. 1999.

VALÉRIO, A. F. et al.Análise da composição florística e da estrutura horizontal de uma Floresta Ombrófila Mista Montana, município de Irati, PR - Brasil. Revista Acadêmica Ciências Agrárias e
Ambientais, Curitiba, v. 6, n. 2, p. 137-147. 2008a. VALÉRIO, A. F. et al.Análise florística e estrutural do componente arbóreo de um fragmento de Floresta Ombrófila Mista em Clevelândia, Sudoeste do Paraná. Revista Acadêmica Ciências Agrárias e Ambientais, Curitiba, v. 6, n. 2, p. 239-248. 2008b. VENZKE, T. S. L. et al.Levantamento florístico de espécies arbóreas e arbustivas em uma área na planície costeira do Rio Grande do Sul. In: CONGRESSO DE INICIAÇÃO CIENTÍFICA, 14., 2005, Pelotas.. Anais... Pelotas: Universidade Federal de Pelotas, 2005.

WATZLAWICK, L. et al. Caracterização da composição florística e estrutura de uma Floresta Ombrófila Mista, no município de General Carneiro (PR). Ambiência,v. 1, n. 2, p. 229-237. 2009. 